\title{
Mudança social: uma arte? \\ Empreendimentos sociais que utilizam a arte como forma de mudança*
}

Marcelo Tyszler**

SumÁrio: 1. Introdução; 2. Problema de investigação e metodologia; 3. Arte como forma de mudança social; 4. Conclusões.

SUMMARY: 1. Introduction; 2. The problem under investigation and methodology; 3 . Art as a form of social change; 4. Conclusions.

Palavras-chave: empreendimentos sociais; terceiro setor; cultura; arte.

KEY WORDS: social enterprises; third sector; culture; art.

Este artigo se propõe a conhecer, analisar e sistematizar, crítica e estrategicamente, o que diferencia os empreendimentos sociais que atuam por meio da arte para obter mudança social, a partir de um estudo qualitativo. A parte inicial aborda a fundamentação teórica, enfocando prioritariamente o conceito de empreendedorismo social. Em seguida, o artigo apresenta o segmento a ser estudado, trazendo as principais sistematizações e constatações feitas a partir do estudo do material inicialmente apresentado, em conjunto com uma série de entrevistas realizadas com gestores desses empreendimentos e agentes de instituições de apoio. As principais características desses empreendimentos são: apelo diferenciado, audiência ampliada, concretização, crença e formação dos gestores, preservação/identidade cultural. Por outro lado, os principais desafios são: consolidação da arte como forma de mudança social, mensuração de resultados e atuação em rede.

\footnotetext{
* Artigo recebido em ago. 2006 e aceito em mar. 2007.

** Bacharel em administração pela FEA/USP, mestre em administração pública pela Eaesp/ FGV. Professor no Centro de Estudos de Política e Economia do Setor Público (Cepesp), da Escola de Economia de São Paulo, da FGV. Endereço: Rua Afonso de Freitas, 287, ap. 82 - CEP 04006-05, São Paulo, SP, Brasil. E-mail: marcelo@tyszler.com.br.
} 
Social change: an art? Social enterprises that use art as a form of change

This article results from a qualitative study intended to understand, analyze and systematize, both critically and strategically, what differentiates social organizations that use art to achieve social change. Initially, it presents the theoretical framework focusing primarily the concept of social organizations. Next, it narrows the analysis to the specific segment under study and summarizes the main findings based on the literature presented in the first part as well as on in-depth interviews with NGO managers and support agency workers. The following characteristics were found: differentiated appeal, broad audience, concretization, managers' background and beliefs, cultural identity/preservation. On the other hand, the main challenges were: consolidation of art as way to achieve social change, result assessment and networking.

\section{Introdução}

Uma das diferentes formas de uma organização buscar mudança social é atuar com atividades baseadas em arte. Conforme articulado pela Unesco, na Conferência Intergovernamental em Políticas Culturais para o Desenvolvimento (Unesco, 2001), bem-estar social e econômico e bem-estar cultural são inseparáveis.

A música, por exemplo, possui o potencial transformador de comunicar uma visão de mudança social e de atingir indivíduos e sociedade. Como dito por Flávio Pimenta, fundador da Organização da Sociedade Civil Meninos do Morumbi, "através da música, os Meninos do Morumbi dão voz à fome, à exclusão, ao abandono, às desigualdades sociais, às situações de risco pessoal e social em que vivem. O papel formador e transformador da arte surge como um grito coletivo pela cidadania" (Meninos, 2003). Isso evidencia o forte apelo que a música possui.

Tais organizações possuem como uma de suas características atuar com classes sociais menos favorecidas e com jovens, o que gera naturalmente uma ligação com a questão da educação não-formal e complementação à educação formal, e um potencial de geração de impacto positivo em políticas públicas.

Além disso, podemos notar que muitos desses empreendimentos fortalecem e/ou desenvolvem a identidade cultural, atingem uma audiência mais ampla que os beneficiários diretos por meio de apresentações/exposições e conseguem tangibilizar alguns dos resultados por meio de gravações musicais, programas de rádio e obras de arte. 
Outra demonstração que evidencia a crescente importância dada a essas organizações é o lançamento por parte do BNDES de uma linha de financiamento chamada transformando com arte, que apóia projetos sociais destinados ao atendimento de crianças e jovens, que utilizem a arte e a cultura, em suas mais variadas linguagens e expressões, nos processos educativos de formação para a vida e para a cidadania. Outras agências de apoio, mesmo sem linhas de financiamento especializadas, apóiam projetos com esse tipo de proposta.

Pretendemos conhecer e sistematizar o que diferencia os projetos que atuam por meio da arte, em termos de forma de atuação e de resultados e conhecer seus desafios. Considerando a dificuldade de uma mensuração mais exata de resultados, optamos por estudar o tema a partir da visão dos seus gestores e apoiadores, entendendo o que esses projetos possuem que estimulam seus gestores a desenvolvê-los e também atraem o suporte de agências de apoio.

O presente artigo procura se concentrar na fundamentação conceitual - empreendimentos sociais - e nas reflexões a respeito dos dados coletados a partir das entrevistas feitas com empreendedores sociais e representantes de agências de apoio.

\section{Problema de investigação e metodologia}

Este artigo teve como objetivo identificar e sistematizar os diferenciais em termos de forma de atuação e resultados dos empreendimentos sociais que utilizam formas de arte para atingir mudanças sociais, segundo a visão de seus dirigentes e das agências de apoio.

Questões de pesquisa diretamente derivadas desse enunciado são:

v para as agências de apoio - por que investir em projetos que utilizam a arte como forma de mudança social?

v para os empreendimentos sociais - por que atuar por meio de projetos que utilizam a arte como forma de mudança social?

Os principais instrumentos para coleta de dados utilizados foram:

$\checkmark$ revisão da literatura;

$\checkmark$ análise de exemplos;

v entrevistas com representantes de empreendimentos sociais e de agências de apoio.

Optamos por realizar a entrevista de forma pessoal ou por telefone, devido a distância. Foram utilizadas perguntas não-estruturadas ou de resposta livre, 
ou seja, "perguntas abertas, que o entrevistado responde com suas próprias palavras" (Malhotra, 2001:281). Com duração média de uma hora, procuramos escutar ao máximo o entrevistado não intervindo durante as explanações.

\section{Empreendimentos sociais}

Para a definição de empreendimentos sociais, os principais referenciais teóricos utilizados são Dees (1994) e Austin e Wei-Skillern (2002). Dees (1994) indica que um empreendimento social diferencia-se dos demais por meio de duas dimensões centrais e quatro dimensões amplificadas.

\section{Dimensões centrais}

As dimensões centrais são:

จ objetivo social - "o objetivo primário de um empreendimento social é manter ou melhorar as condições sociais de um modo que vá além dos benefícios financeiros criados para financiadores, gestores, empregados ou consumidores de uma organização" (Dees, 1994:1). Objetivo social, propósito social, fim social é apresentado como uma rápida referência a "fazer o mundo um lugar melhor, em alguma forma normativa de melhor". O benefício almejado por um empreendimento social pode ser direcionado, por exemplo, diretamente para um grupo com condições ruins, para uma comunidade ou para futuras gerações, entre outros;

- método social - "para atingir seus objetivos primários, o empreendimento social se apóia na boa vontade (motivações comunais, altruístas, afiliativas ou não-pecuniárias) de, pelo menos, alguns de seus stakeholders chave" (Dees, 1994:3). Entendemos, também, por método social um comportamento ético e adequado aos fins do empreendimento, ou seja, no conceito de que os fins não justificam os meios, em que um certo grau de sacrifício pessoal é esperado.

\section{Dimensões amplificadas}

São dimensões amplificadas:

- sacrifício de retorno financeiro aos financiadores - "os fundadores e principais financiadores de um empreendimento social submetem-se a aceitar retornos menores que taxas de mercado em seus investimentos - talvez 
nenhum retorno - com o propósito de permitir o desenvolvimento do propósito social da organização" (Dees, 1994:4);

\ motivação social da força de trabalho - "a força de trabalho central em um empreendimento social é motivada de forma significativa pelo retorno não pecuniário associado à missão social da organização" (Dees, 1994:4);

v precificação abaixo do custo para os consumidores - "os consumidores ou beneficiários primários das atividades de um empreendimento social não são obrigados a pagar o custo total de produção (incluindo uma taxa de mercado de retorno sobre o capital investido)" (Dees, 1994:5);

、 governança orientada pela missão - "governança de um empreendimento social tende a tomar a forma de um conselho que se baseia no senso de representatividade da missão social da organização, derivando sua autoridade desta missão".

Assim, o conceito de empreendimentos sociais utilizado no estudo é organizações, programas ou projetos que possuam prioritariamente um fim social ou uma finalidade pública e que utilizem um método social para atingi-lo.

\section{Arte como forma de mudança social}

Se considerarmos os seguintes componentes de uma ação social: público-alvo, área de atuação e a forma dessa atuação, certamente público-alvo será o mais fácil de classificar.

Tomando como referência a pesquisa "Alianças estratégicas intersetoriais para atuação social" (Fischer, 2003), o público atendido prioritariamente é formado por crianças e adolescentes, indicado como público beneficiário por 79\% da amostra dessa pesquisa. São citados ainda, como públicos, comunidade local, portadores de deficiência, idosos, entre outros.

Por outro lado, identificar áreas e formas de atuação para mudança social não é uma análise das mais simples. Tomando como base o mesmo estudo, são indicadas como áreas: educação (apontada por 63,6\% da amostra), meio ambiente (com 42,6\%), desenvolvimento comunitário (41,8\%), arte e cultura (40,8\%), entre outras. Porém, como os próprios números e a própria pesquisa indicam, só nessas categorias já é possível uma grande sobreposição: um projeto de desenvolvimento comunitário que trabalha a temática do meio ambiente pode ser classificado apenas como desenvolvimento comunitário, como meio ambiente, ou ambos, por exemplo. Tais fatos podem ocorrer, por exemplo, dependendo da forma de coleta dos dados. 
É possível notar uma potencial confusão, para fins de registro e classificação, sobre áreas e formas de atuação. Exemplos claros desse tipo potencial de confusão entre áreas e formas de atuação podem ser encontrados no material da Unesco disponível na internet (Castro, 2003) - um dos melhores referenciais sobre o tema em termos de dados consolidados. Nesse banco de dados de experiências em educação, cultura, lazer, esporte e cidadania com jovens é utilizada a nomenclatura objetivos e atividades, de forma quase análoga à nomenclatura áreas e formas, respectivamente. Na base de dados, a menção à arte é feita, na maioria das vezes, em atividades e objetivos, ou apenas em atividades. Por vezes é feita apenas em objetivos e às vezes nem é feita, mesmo que o projeto tenha atividades relacionadas a formas de arte, ou que isso já esteja explícito no título do projeto.

Se criar classificações que permitam registrar os projetos que trabalham com arte já é uma dificuldade, podemos concluir que encontrar dados agregados sobre essa temática fica mais difícil ainda. Apesar das dificuldades reveladas no estudo da Unesco um grande mérito que ele possui é o de ter o item atividades, que acaba funcionando como o melhor filtro para identificar os projetos que trabalham com arte.

Mesmo com poucos dados agregados sobre a atuação social por meio das artes, alguns indícios revelam a importância e legitimidade que essa forma de atuação vem recebendo.

BNDES, Vitae e Ashoka, como agências de apoio, possuem em seu portfólio iniciativas que contemplam essa forma de empreendimentos sociais.

Depois de realizar por três anos seguidos a mostra BNDES Arte em Ação Social, em conjunto com o seminário Transformando com Arte: Compartilhando Experiências, em que houve participação de órgãos como Unesco, Fundação Ford e Usaid, o BNDES lançou uma linha de financiamento em novembro de 2002 intitulada justamente Transformando com Arte. Buscando apoiar projetos que utilizavam a arte como forma de mudança social, voltados a crianças e adolescentes em situação de risco social, o banco recebeu 1.342 inscrições de todo o Brasil e selecionou 52 para receber um aporte total de $\mathrm{R} \$ 4,8 \mathrm{mi}$ lhões (BNDES, 2003).

A Fundação Vitae possui uma linha de apoio a projetos de atendimento a crianças e jovens, para a implantação de atividades educativas, culturais e esportivas. Dos 12 projetos diretamente apoiados pela fundação na última edição publicada em seu site (Vitae, 2003), oito indicam em seus títulos de projeto que utilizam formas de arte para desenvolver o trabalho.

A Ashoka (Boletim Ashoka, 2001) publicou edição especial de seu boletim dando atenção aos projetos apoiados que utilizam a arte como forma de obter mudança social. 
Em 2001 a Unesco do Brasil lançou a publicação Cultivando a vida, desarmando violências, outra iniciativa importante, onde pesquisou iniciativas em educação, cultura, lazer, esporte e cidadania com jovens. Com um levantamento de 222 projetos "o livro da Unesco registra uma tendência que se espalha pelo Brasil: o uso da arte, por organizações não-governamentais e poder público, como instrumento de socialização entre jovens" (A Vida, 2001). Segundo a coordenadora da pesquisa da Unesco, Mary Garcia Castro, citada por A Vida (2001), "a violência é incompatível com o belo, daí a importância da arte (...) o mérito desses trabalhos é fazer do jovem o protagonista de sua mudança. Com a arte, eles são criadores e criaturas, assim como os pintores".

O site Aprendiz (ONGs, 2003), a revista Educação (A Vida, 2001), os jornais Valor e Gazeta Mercantil vêm publicando matérias de empreendimentos sociais que utilizam a arte como forma de mudança social, revelando o espaço na mídia e na sociedade que essa forma de atuação social vem ganhando.

\section{Características e desafios da atuação social por meio da arte}

Nesta seção serão sistematizadas as análises feitas em relação aos diferenciais, em termos de formas de atuação e resultados, e os principais desafios dos empreendimentos sociais que utilizam a arte como forma de mudança social, na visão de seus gestores e das agências de apoio.

De um modo geral, empreendimentos sociais que utilizam a arte como forma de atuação social possuem como características: apelo diferenciado; audiência ampliada; concretização da ação; crença e formação dos empreendedores; preservação/identidade cultural.

Em termos de desafios nota-se as questões de consolidação da arte como forma de mudança social, mensuração de resultados e atuação em rede.

\section{Apelo diferenciado}

Há algo de contagiante, diferente, descontraído em um primeiro momento, com um apelo diferenciado quando se trata de uma atuação por meio da arte. Por mais complexa e abstrata que pareça tal afirmação é impossível negar esse aspecto que sempre sobressai no discurso dos entrevistados e das organizações.

Valarelli (2003), do Projeto Carmim, explica isso dizendo que a arte é outra linguagem, muitas vezes não-verbal, que indica outra forma de comunicação. Ela desperta o curioso nas pessoas. Vira uma maneira diferente de superar obstáculos ou de descobrir potenciais adormecidos justamente por utilizar essa linguagem diferente, que não tem os vícios e bloqueios da linguagem 
usual do cotidiano. Randi (2003), da Fundação Orsa, diz que essa linguagem ajuda na redução de possíveis resistências, fortalecendo o trabalho de mudança social objetivado pelo projeto. Marino (2003) e Randi (2003) complementam dizendo que por meio da arte se consegue transmitir aspectos que o "óbvio" da educação formal não consegue.

Um exemplo do apelo diferenciado é a banda Arrasta-Lata. Situação única entre os projetos da instituição Arrastão, existe fila de espera das crianças para entrarem na banda, e estar nela é como uma bonificação. Segundo Joílson (2003) muitas pessoas do Arrastão, mesmo não fazendo parte da banda, querem assistir aos ensaios.

"O trabalho é legal", "alegre", "contagiante" são expressões comuns entre os gestores desses empreendimentos. Eles dizem que o apelo diferenciado que a atividade artística possui é importante para mostrar a importância de valores como disciplina, exercícios, técnica, esforço e dedicação, realizando desse modo um trabalho de promoção humana.

Os Meninos do Morumbi (2003) e Valarelli (2003) dizem que a atuação dá voz aos anseios, problemas e, em última análise, ao interior do beneficiário. Tudo isso é comunicado por meio de uma linguagem que, da forma tradicional, jamais seria possível, e isso é um fator contagiante.

\section{Audiência ampliada}

Ligada à questão do apelo diferenciado, pode-se dizer que, como o contágio não chega apenas ao beneficiário direto da ação, a atuação por meio da arte atinge uma audiência ampliada.

Segundo Valarelli (2003), ao ver um grupo de pessoas pintando, por exemplo, um observador externo no mínimo pára querendo ver o que está acontecendo e pode até querer se integrar na atividade. Joílson (2003) do Arrasta-Lata reforça esse aspecto dizendo que as apresentações chamam muito a atenção do público. Essa afirmação, apesar de parecer simples, representa um aspecto interessante dos projetos que utilizam arte, que é um forte potencial de disseminação, como colocado por Randi (2003), da Fundação Orsa.

Em caso citado por Falander (2003), da Fundação Ashoka, a banda do projeto Afro-Reggae foi a primeira banda de projetos sociais a obter um bom contrato com uma grande empresa da indústria fonográfica. Os Meninos do Morumbi já fizeram apresentações em vários locais do mundo.

Isso revela que o trabalho feito por meio da arte acaba por levar à proposição de valor, e a missão dos empreendimentos sociais a um público além do beneficiário direto de sua ação. 
Com esse poder de levar a mensagem ao grande público ou outros públicos que não os beneficiários diretos da ação, a atuação social por meio da arte acaba por criar um outro canal para levar sua proposição de mudança social. Logo, além de promover seu trabalho junto aos beneficiários diretos, são sensibilizados e mobilizados para a causa outros públicos também importantes para a mudança social pretendida. Podemos citar o caso do Projeto Carmim, em que os médicos acabam sendo sensibilizados e conscientizados para a importância de um tratamento focado na pessoa como um todo, e não apenas na doença ou no número do leito, como diz Valarelli (2003). Segundo Randi (2003), esse aspecto confere aos projetos com arte uma maior facilidade de disseminação.

Outra vantagem relacionada a isso, para os empreendedores, é o desenvolvimento de uma nova experiência para os beneficiários diretos. De acordo com Joílson (2003), o fato de as crianças e jovens da banda Arrasta-Lata saírem para fazer apresentações lhes dá mais confiança e experiência de vida. Por causa da banda Meninos do Morumbi, por exemplo, os jovens puderam conhecer localidades da Europa. Fatores semelhantes ocorrem no Projeto Bate-Lata, apoiado pela Fundação Orsa.

\section{Concretização}

O trabalho feito por meio da arte possui como característica o aspecto da concretização, da tangibilização. Isso ocorre porque essa forma de trabalho, apesar de ter em sua essência questões sutis, abstratas, na linguagem diferenciada que é a arte, tem por forte característica criar símbolos constantemente.

A cada apresentação de uma banda, de um balé ou teatro, a cada tela pintada, um símbolo da evolução do trabalho está sendo criado. Valarelli (2003) refere-se a isso como um legado dos empreendimentos, algo concreto que o beneficiário olha e pode dizer "eu fiz isso".

Esse fator peculiar ao trabalho com arte o diferencia de outras possíveis formas de atuação e auxilia em levar a mensagem para a audiência ampliada. Ao simples olhar para as telas, escutar uma das apresentações de uma banda ou assistir a uma peça, o observador rapidamente capta a essência da proposição de mudança social que se quer levar. É importante deixar claro que isso não exime os empreendedores de ter uma ação embasada, uma vez que o produto da arte em si não é o mais importante. Falander (2003), da Fundação Ashoka, enfatiza esse ponto, dizendo que usar ou não usar a arte, apenas, não diz nada, mas sim como isso é feito.

O fato é que existe uma constante criação de símbolos que sozinhos guardam em si parte da mudança feita. Caso o trabalho esteja sendo bem conduzido de fato, isso só irá ajudar a ampliar seus resultados. 
Existe, entretanto, o possível lado negativo. Apesar de ter sua disseminação e divulgação facilitada por esse aspecto, Randi (2003), Marino (2003) e Joílson (2003) alertam para o perigo de que um determinado projeto possa vir a se tornar "produto de mercado", sendo utilizado apenas para fins comerciais ou publicidade excessiva/inadequada por parte da própria instituição ou de seus apoiadores.

\section{Crença e formação dos gestores}

O porquê de utilizar a arte ou um determinado tipo de arte como fator central do empreendimento social está quase sempre relacionado com a formação do empreendedor. Em geral os projetos com música são liderados por pessoas que já possuíam experiência e/ou formação em música, os projetos com artes plásticas idem. Essas pessoas ao decidirem desenvolver um empreendimento social foram buscar uma ferramenta, e em geral essa estava em sua formação.

Outra característica talvez não peculiar aos empreendimentos sociais que trabalham com arte, porém forte nesse grupo, é a crença por parte dos seus gestores no real valor e efetividade de sua proposta de atuação social. Ao serem indagados com questões do tipo "você acredita que esse trabalho com arte que você realiza é uma das melhores formas de atingir mudança social", os entrevistados têm poucas dúvidas em dizer sim.

Longe de querer ter um juízo de valor sobre se esse aspecto é positivo ou negativo, é muito interessante perceber a paixão e a crença que esses empreendedores têm em seus projetos.

Esse ponto talvez seja uma das principais diferenças de visão e preocupação quando se compara o grupo dos empreendedores com o dos apoiadores. Enquanto os gestores apresentam essa paixão latente, os apoiadores são mais cautelosos, possuindo inclusive uma visão mais sistêmica.

Falander (2003), ao ser indagada do porquê investir em projetos que utilizam arte como forma de mudança social, rapidamente explica que não investe nesse tipo de projeto. Segundo a entrevistada, no caso da Ashoka, o investimento é feito em empreendedores sociais que apresentam potencial de impacto e mudança de paradigmas e que apenas o fato de utilizar a arte não deve pesar na seleção. Caso seja uma ferramenta que se mostre válida no projeto em especial, será aceita. Para ela, apesar de não haver uma clara regulação nesse sentido, para agência é positivo ter um portfólio diversificado de formas de atuação, para uma maior riqueza de ações sociais na rede de empreendimentos apoiados. No caso da Vitae, de acordo com Marino (2003), existe um aspecto interno da organização que é a ênfase nas atividades com cultura, 
sendo que, na área de promoção social, a ênfase de uma forma geral é em projetos de educação não-formal.

Randi (2003) mostra ainda que nos projetos desenvolvidos pela Fundação Orsa, procura-se conhecer a realidade e os recursos materiais e humanos locais para se escolher a forma de arte que será utilizada.

Entretanto, o que une os dois grupos em relação ao aspecto da crença é que ambos esperam que os projetos venham a crescer, impactar direta ou indiretamente outros empreendedores, servir de referência, serem replicados e virem inclusive influenciar na formação de políticas públicas.

Valarelli (2003) cita dois exemplos que são indícios do desenvolvimento desses projetos como forma de influenciar políticas públicas: aulas para os alunos de medicina na Universidade de São Paulo, para a qual já foi convidado a ministrar nos últimos anos, revelando uma preocupação da universidade em ampliar o perfil do seu egresso; e uma capacitação que promoveu em parceria com os Doutores da Alegria com orientação do Ministério da Saúde focado em profissionais da saúde da rede pública.

Falander (2003) também reforça a importância disso. Ela indica que a ampliação do impacto de um empreendimento pode ocorrer:

、 diretamente - por uma replicação ou ampliação que o próprio empreendedor conduz;

v indiretamente - com o empreendedor influenciando outros empreendedores a seguir seus modelos.

Sobre a influência em políticas públicas ela cita o exemplo de um empreendimento relacionado à eletrificação de regiões rurais, em que uma proposta inovadora e mais barata era utilizada. O empreendimento obteve um sucesso tão grande que recebeu apoio do BNDES e do governo e foi replicado por quatro outros estados do país.

A Fundação Orsa, segundo Randi (2003), tem essa sistematização e viés de replicação em sua própria missão. Marino (2003), da Fudanção Vitae, diz que em geral se espera que os projetos evoluam nesse sentido, porém não é esse o trabalho da fundação, exceto em casos especialmente solicitados pelo governo.

\section{Preservação/identidade cultural}

Uma última característica dos empreendimentos sociais que utilizam a arte é que acabam contribuindo para um movimento de preservação cultural, em alguns momentos, e até mesmo de desenvolvimento e fortalecimento de uma identidade cultural. 
Falander (2003) cita alguns exemplos de trabalhos com índios que trabalhavam justamente a questão do resgate cultural e preservação de sua cultura. As bandas de projetos voltados à música em geral buscam trabalhar uma musicalidade brasileira. A banda da Mangueira, por exemplo, tem por intuito preservar e fortalecer o senso de identidade cultural daquela comunidade.

Randi (2003) refere-se ao exemplo da atuação social em Campinas, onde o projeto da banda Bate-Lata ajudou a fortalecer o senso de identidade da localidade e sempre que a banda é divulgada, todos da região se sentem prestigiados, mesmo que não atuem nela diretamente. Dessa forma, além da busca do objetivo social, os empreendimentos têm também essa função de manter e resguardar a cultura. Essa afinidade com a cultura pode ser também, por outro lado, um dos fatores que contribuem com interesse dos participantes, já que falam diretamente a fatores peculiares de cada comunidade.

\section{Consolidação da arte como forma de mudança social}

Apesar de todo o espaço que essa forma de atuação social vem ganhando recentemente, ainda é necessária uma consolidação desse setor. É preciso convencer e mostrar para a sociedade e os apoiadores o poder transformador que a arte possui.

Valarelli (2003), que é fellow da Ashoka, conta que não foi fácil obter o apoio por parte da instituição. Segundo ele, foi um processo de nove meses para convencer o conselho da instituição da validade e poder de transformação do projeto. E há ainda uma resistência na própria Ashoka e em outros organismos de apoio em aceitar projetos com arte como realmente válidos de provocar uma transformação social. Tal resistência pode ser causada, também, pela conduta mais cautelosa e visão mais sistêmica em relação à visão dos empreendedores que essas agências costumam apresentar.

Tanto os empreendedores quanto as agências de apoio citam as ações do BNDES como importantes sinalizadores na consolidação desse setor. Porém, é difícil uma visualização ainda clara do setor, pois as próprias organizações que atuam por meio da arte não se enquadram, em seus discursos, como parte de um setor que atua com arte para a mudança social.

Outro ponto para a consolidação do setor é uma caracterização mais precisa do que é essa forma de atuação social. Apoiando-se principalmente na fala de Valarelli, do Projeto Carmim, é importante diferenciar um trabalho de arte para mudança social de uma simples arte-educação, arte-terapia e principalmente, recreação. $\mathrm{O}$ trabalho com arte sofre ainda de um dos problemas dos empreendimentos sociais, que é considerar que só pelo fato de uma causa ser boa, o empreendimento também será, automaticamente. É necessário ter 
muito claros os objetivos do programa e como serão realizados, ou seja, criar uma metodologia, termo enfatizado pelo idealizador do Projeto Carmim. Para ele existe um risco muito grande de pessoas sem uma metodologia estruturada promover atividades que não passam de uma recreação e de fato os efeitos de promoção humana e social ficarem como colaterais e não controlados, podendo até não ocorrer. Marino (2003) reforça esse aspecto dizendo que é importante ter muito claro que o objetivo principal não é formar artistas e sim promover a mudança social.

Falander (2003) de certo modo apóia essa preocupação, dizendo que as leis de incentivo cultural, por exemplo, de um lado incentivam a propagação desses projetos, mas podem ter o efeito colateral negativo de também promover um crescimento de ações ineficazes.

Outro aspecto levantado por Marino (2003) é que esses projetos podem vir a criar um ambiente seguro, um mundo paralelo especial, até mesmo fantasioso, do qual os jovens não querem sair. Aspectos como esses são vistos nos diversos projetos quando os jovens atingem uma idade na qual devem deixar o grupo. Por isso, é muito importante que durante o desenvolvimento do trabalho se tenha em mente como os jovens atendidos irão se comportar no ambiente fora da instituição, tendo de atuar, eventualmente, no mercado de trabalho.

Tendo uma metodologia estabelecida, o desafio seguinte é comprovar os resultados dos projetos, como será visto a seguir.

\section{Mensuração de resultados}

Um dos grandes desafios do grupo de empreendimentos sociais que trabalham com arte, apontado por todos os entrevistados, é desenvolver indicadores e medir resultados desses projetos.

Segundo Falander (2003), esse trabalho com arte lida com a atitude das pessoas, e isso é muito difícil de medir. Para ela, indicar apenas o número de pessoas atendidas não é um indicador válido, pois nada fala a respeito da qualidade da forma do trabalho. Em exemplo citado por ela, os Doutores da Alegria $^{1}$ desenvolveram alguns indicadores como número de vezes em que o médico tocou a criança, número de vezes em que a criança sorria e redução do

\footnotetext{
${ }^{1}$ Doutores da Alegria não trabalham com arte como forma de mudança social, apenas procuram melhorar o ambiente hospitalar. Porém, pela sinergia com o Projeto Carmim, em relação ao público e local de atuação, o exemplo foi citado.
} 
tempo de internação. Randi (2003) cita exemplos de importantes personagens locais, como bandidos que deixaram de atuar na criminalidade para auxiliar nos projetos. Ele indica que, apesar de parecer pouco em termos quantitativos, por ser um ou dois em algumas localidades, o peso que isso possui sobre a comunidade é muito grande.

No Projeto Arrastão foi muito difícil encontrar algum indicador mais quantitativo da melhoria social. Joílson (2003), no entanto, era capaz de relatar pontos mais qualitativos, como depoimentos de crianças e público. Algumas crianças, por exemplo, passam a estudar mais na escola para poder continuar na banda e algumas até usam o raciocínio matemático dos exercícios de percussão para as aulas de matemática na escola. No Projeto Carmim, além dos relatos, consideram-se como indicadores o número de aulas dadas, o que revela o interesse do público atendido, e o número de produção plástica. Como indicadores qualitativos, temos o fato de os pacientes se mostrarem mais colaborativos, com melhor humor. É visto, também, o efeito nos próprios médicos.

Marino (2003), da Fundação Vitae, diz que não possui um estudo mais aprofundado da utilização da arte, mas possui alguns indicadores que mostram um aumento acima do esperado na leitura, em projetos relacionados a teatro e literatura, e que o aspecto da convivência é sempre destaque nos projetos com arte quando comparados com os demais.

Valarelli (2003) conta, ainda, que já está sendo estruturado um estudo comparativo para analisar o caminho, no hospital, de pacientes atendidos pelo Carmim e pacientes não atendidos pelo Carmim.

\section{Atuação em rede}

Ao serem questionados sobre a atuação em rede, todos dizem ser importante, porém fazem algumas ressalvas. Joílson (2003), do Projeto Arrastão, diz acreditar que haja muita resistência e que organizações mais antigas acabam vendo novos projetos como concorrentes.

Valarelli (2003) diz que em tese é muito positiva a idéia da rede, porém há sim uma grande resistência, concorrência, especialmente por fontes de apoio e, muitas vezes, comportamento não ético de alguns empreendedores.

Pudemos perceber que muitas das organizações conhecem, ao menos superficialmente, algumas das demais organizações, porém há pouco diálogo.

Falander (2003) revela que entre os empreendedores apoiados pela Ashoka já há uma rede geral, porém existe uma iniciativa de criar uma subrede apenas entre os empreendedores que trabalham com arte. Na sua visão, 
entre os empreendedores do portfólio da Ashoka, não existe uma concorrência direta, pois já possuem o apoio e procuram atender públicos e regiões diferentes. Segundo ela, essa diversidade é importante e a troca é sempre positiva, citando exemplos em que essa troca resultou em benefícios mútuos.

Marino (2003) diz acreditar que a rede é muito fragilizada pela constante demanda que esses empreendimentos têm por outros aspectos de sua gestão e sustentabilidade. Por isso, é essencial o papel dos financiadores para iniciar e consolidar uma rede.

\section{Conclusões}

Neste artigo procuramos identificar os diferenciais, em termos de forma de atuação e resultados, dos empreendimentos sociais que utilizam a arte como forma de mudança social, segundo a visão dos gestores e das agências de apoio. Procuramos, também, conhecer os desafios para esse setor, bem como as consonâncias e dissonâncias entre os grupos estudados.

Em termos de caracterização, podemos dizer que os empreendimentos sociais que utilizam a arte como forma de mudança social possuem um apelo diferenciado, atingem uma audiência ampliada, obtêm concretização da ação, recebem forte apoio da crença e formação dos empreendedores e acabam por agir, também, na preservação e identidade cultural.

Em termos de desafios, os principais pontos são a consolidação da arte como forma de mudança social, a necessidade da elaboração de mecanismos para a mensuração de resultados e atuação em rede, vista como positiva porém com ressalvas.

É importante destacar que, ao se comparar o grupo das agências de apoio com o dos empreendimentos sociais, os pontos observados em geral são muito semelhantes, apesar de o teor do discurso ser um pouco diferenciado. No lado dos empreendedores sociais, destaca-se a forte presença da paixão pelo que fazem e o fato de essa forma de atuação ser uma das melhores soluções para promover a mudança social. No lado das agências de apoio, a postura é mais cautelosa e a visão é mais sistêmica, no sentido de procurar incentivar uma diversidade de formas de ação.

Ambos os grupos, no entanto, concordam que é importante consolidar o setor, desenvolver métricas para comprovar resultados e esperam que o trabalho venha a ter seu impacto ampliado, seja pelo crescimento de cada empreendimento, pela influência que ele possa gerar nos beneficiários diretos e indiretos, em demais membros da sociedade ou ainda influenciando diretamente na elaboração de políticas públicas e ações governamentais. 


\section{Referências bibliográficas}

A VIDA é bela. Revista Educação, n. 246, out. 2001. Disponível em: <www.uol.com.br/ aprendiz/n_revistas/revista_educacao/outubro01/aprendiz.htm $>$.

ALMEIDA, Martinho Isnard Ribeiro de. Manual de planejamento estratégico: desenvolvimento de um plano estratégico com a utilização de planilhas Excel. São Paulo: Atlas, 2001.

AUSTIN, James; WEI-SKILLERN, Jane. Entrepreneurship in the social sector: course overview. Fall 2002.

BNDES promove debate sobre uso da arte na formação de jovens em situação de risco social. Disponível em: <www.bndes.gov.br/noticias/not557.asp>.

BNDES seleciona, para apoio, 52 projetos sociais que utilizam a arte e a cultura na educação de crianças e adolescentes. Disponível em: <www.bndes.gov.br/noticias/not576.asp>.

BOLETIM ASHOKA: arte-educação, maio 2001. Disponível em: <www.ashoka.org.br/ comunicacao/index.jsp $>$.

BORTOLI NETO, Adelino de. As dificuldades para a implementação de estratégias em uma empresa familiar de pequeno porte. In: ENANPAD, 22. Anais... São Paulo: Anpad, 1998.

BUTLER, R. Managing voluntary and non-profit organizations: strategy and structure. Routledge, 1990.

CASTRO, Mary et al. Cultivando a vida, desarmando violências. Unesco, 2001.

. Experiências em educação, cultura, lazer, esporte e cidadania com jovens. Unesco, 2003. Disponível em: <www.unesco.org.br/pesquisa/default.asp>.

DEES, J. G. Social enterprise: private initiatives for the common good. Class Note, Nov. 1994.

. Enterprising nonprofits. Harvard Business Review, p. 55-67, Jan./Feb., 1998.

DRUCKER, P. What business can learn from nonprofits. Harvard Business Review, p. 88-93, July/Aug. 1989.

. Administração em organizações sem fins lucrativos: princípios e práticas. 5. ed. São Paulo: Pioneira, 2001.

FALCONER, Andres Pablo. A promessa do terceiro setor: um estudo sobre a construção do papel das organizações sem fins lucrativos e do seu campo de gestão. Dissertação (Mestrado) — Faculdade de Economia, Administração e Contabilidade da Universidade de São Paulo, São Paulo, 1999. 
FERNANDES, R. C. O que é o terceiro setor. In: Terceiro setor: desenvolvimento social sustendado. Rio de Janeiro: Gife, 1997.

FISCHER, Rosa Maria. Alianças estratégicas intersetoriais para atuação social: relatório final, 2003.

FISCHMANN, Adalberto A.; ALMEIDA, Martinho I. R. Planejamento estratégico na prática. São Paulo: Atlas, 1991.

. Implementação de estratégias: identificação e análise de problemas. Tese (LivreDocência) - Faculdade de Economia, Administração e Contabilidade da Universidade de São Paulo, São Paulo, 1987.

FUNDAÇÃO ORSA. 2003. Disponível em: <www.fundacaoorsa.org.br>.

FUNDAÇÃO VITAE. 2003. Disponível em: <www.vitae.org.br>.

HUDSON, M. Administrando organizações do terceiro setor. São Paulo: Makron Books, 1999.

KOTLER, Philip. Administração de marketing. São Paulo: Prentice Hall, 2000.

LETTS, C. W.; RYAN, W.; GROSSMAN, A. Virtous capital: what foundations can learn from venture capitalists. Harvard Business Review, p. 36-44, Mar/Apr 1997.

MALHOTRA, Naresh. Pesquisa de marketing: uma orientação aplicada. 3. ed. Porto Alegre: Bookman, 2001.

MAXIMIANO, A. C. Amaru. Introdução à administração. 4. ed. São Paulo: Atlas, 1995.

MENINOS DO MORUMBI. Disponível em: <www.meninosdomorumbi.org.br>. Acesso em: 2003.

MINTZBERG, H. The rise and fall of strategic planning: reconceiving roles for planning, plans, planners. New York: Free Press; Toronto: Maxwell Macmillan Canada, 1994. Hall, 1996.

; QUINN, J. B. Strategy process: concepts, contexts, cases. New Jersey: Prentice ; AHLSTRAND, B.; LAMPEL, J. Safári de estratégia. São Paulo: Bookman, 2000.

MOORE, Mark. H. Managing for value: organizational strategy in for-profit, nonprofit and governmental organizations. Nonprofit and Voluntary Sector Quarterly Supplement, v. 29, n. $1,2000$.

ONGS descobrem na arte o caminho para salvar educação. 2003. Disponível em: <www.uol.com.br/aprendiz/n_noticias/fazendo_diferenca/id160201.htm>.

PROJETO ARRASTÃO. 2003. Disponível em: <www.arrastao.org.br>. 
PROJETO CARMIM. 2003. Disponível em: <www.carmim.org.br>.

RITS (Rede de Informações para o Terceiro Setor). Disponível em: <www.rits.org.br>. Acesso em: mar. 2002.

SALAMON, L. M. A emergência do terceiro setor: uma revolução associativa global. Revista de Administração da USP, v. 33, n. 1, 1998.

SELLTIZ, Claire. Métodos de pesquisa nas relações sociais. São Paulo: EPU, Universidade de São Paulo, 1974.

SOBANSKI, André Rubini. Implementação de estratégias: estudo exploratório de alguns fatores críticos. Dissertação (Mestrado) — Faculdade de Economia, Administração e Contabilidade da Universidade de São Paulo, São Paulo, 1995.

STONER, J. A. F. Administração. São Paulo: LTC, 1995.

TENÓRIO, F. (Org.). Gestão de ONGs: principais funções gerenciais. Rio de Janeiro: FGV, 1997.

TYSZLER, Marcelo; BARBERO, Edson. Planejamento estratégico em organizações do terceiro setor: o caso do Instituto de Estudos e Orientação à Família. São Paulo: Semead, 2002.

UNESCO. Intergovernmental Conference on Cultural Policies for Development. 2001. Disponível em: <www.unesco.org/culture/laws/stockholm/html_eng/index_en.shtml>.

VITAE. Relatório 2002.

\section{Entrevistas concedidas ao autor}

FALANDER, Claire. 2003.

JOÍLSON. 2003.

MARINO, Eduardo. 2003.

RANDI, Alexandre. 2003.

VALARELLI, Eduardo. 2003. 